\title{
FORMATION PROCESSES OF ICE FABRIC PATTERN IN ICE SHEETS
}

\author{
by
}

N. AzUMA

Department of Applied Physics, Faculty of Engineering, Hokkaido University, Sapporo, Japan 060

A. Higashi

Division of Natural Sciences, International Christian University, Mitaka-shi, Tokyo, Japan 181

\section{ABSTRACT}

Experimental studies on the formation process of the single maximum fabric of ice from its random fabric were carried out using both Greenland Dye-3 ice cores and artificially grown polycrystalline ice. From the observations of the rotation of $\mathrm{c}$-axes of individual grains in thin specimens, an empirical equation was obtained for describing the rotation process of c-axes. Combined with another empirical equation on the relationship between the uniaxial strain of whole specimen and the uniaxial strain in individual grains of different c-axis direction, an equation was derived which describes the formation of single maximum fabric in bulk ice samples.

Computer simulation of the formation process was performed based on an equation starting from an artificially made random fabric pattern. From the results obtained by a stepwise simulation of $2 \%$ strain intervals, the degree of concentration expressed by $\theta_{m}$ the angle which halves the number of grains in the fabric diagram is correlated with the accumulated strain in bulk ice (Fig. 8). The strain deduced by applying this relationship to the obtained $\boldsymbol{\theta}_{\mathrm{m}}$ for samples of Dye-3 ice core coincided well with actual strain which the samples had experienced. This implies that the equation is valid and the mechanism of $\mathrm{c}$-axis rotation prevails in polar ice sheets.

\section{INTRODUCTION}

The formation mechanism of the characteristic fabric pattern of ice in various ice masses on the earth is of vital importance for interpretations of the flow history of ice masses, and for prediction of changes in properties and behavior of ice. It is generally recognized that the fabric pattern of ice in polar ice sheets gradually changes from a random pattern near the surface to the single maxima at depth.

Laboratory experiments have revealed the kinds of characteristic fabrics that can be obtained under certain conditions of the deformation of ice; the small girdle fabric pattern was obtained by the uniaxial compression test (Steinemann 1958, Watanabe and Oura 1968, Tanaka 1972 and Huang, Ohtomo and Wakahama 1983), and a single maximum or two-maximum fabric was developed by simple shear experiments (Shumskii 1958, Rigsby 1960, Kamb 1972 and Duval 1981). However, no detailed experiments or analyses have been carried out clarifying mechanisms of the development of preferred orientation of c-axes in various experiments.

In general, the following can be considered as the three main mechanisms for the development of the ice fabric:

1) rotation of basal plane acompanied by deformation

2) grain growth

3) recrystallization

Although processes in natural ice masses should be governed by combinations of these mechanisms, it is desirable to study experimentally how these mechanisms contribute the formation of characteristic fabric pattern. In polar ice sheets where ice temperatures are very low, mechanisms (1) and (2) are considered to prevail over (3). With respect to (1), it has been reported that the c-axis rotated towards the compression axis when a single crystal of ice was subjected to uniaxial compression (Jones and Brunet 1978), and also when a thin specimen of polycrystalline ice was compressed (Wakahama 1964). However, the rotation angle of the c-axis was not correlated to the amount of uniaxial strain and this phenomenon was not considered to be related to the process of the fabric formation.

In the present work, the quantitative relationship between the rotation angle of $\mathrm{c}$-axis and the amount of uniaxial strain was obtained from uniaxial compressive deformation experiments using thin specimens of polycrystalline ice. Deformation experiments of the same type were carried out for bulk specimens cut from an ice core taken from shallow depth in Greenland ice sheet. Random fabric of this core changed to the broad single maximum when the uniaxial strain reached $10 \%$, and it is inferred that the same mechanism of c-axis rotation takes place in bulk polycrystalline ice when neither grain growth nor recrystallization take place in the process. Computer simulations were performed for the production of single maximum fabric using a constitutive equation describing the relationship between the rotation angle of $\mathrm{c}$-axis and the amount of uniaxial strain.

\section{EXPERIMENTAL PROCEDURES}

Specimen preparation

In order to observe the rotation process of the c-axis of individual grains during the compressive deformation, thin specimens $2 \mathrm{~mm}$ thick and $30 \times 20$ $\mathrm{mm}^{2}$ in area were prepared from both Dye- 3 ice core and artificially grown polycrystalline ice. The latter was grown from the surface of pure water at a moderate rate, so that the c-axes became horizontal under a certain depth. When thin specimens were cut horizontally from this ice, it had two-dimensional random orientation fabric of c-axes. Its average grain size was $2 \mathrm{~mm}$.

In the case of Dye-3 ice core (sample 1851, $1900 \mathrm{~m}$ depth and sample 1950, $2000 \mathrm{~m}$ depth), thin specimens were cut from the core so that the plane of the wide area was parallel to the core axis and its long axis made $45^{\circ}$ with the core axis. Since both cores have the single maximum fabric, the c-axis of each grain lies on the plane of the thin specimen and angles between the compressive axis and the mean direction of $c$-axes of both cores are $40^{\circ}$ and $60^{\circ}$ respectively, with a standard error of $10^{\circ}$. Average grain sizes for the cores of sample 1851 and sample 1950 were $1.5 \mathrm{~mm}$ and $2.7 \mathrm{~mm}$ respectively.

For a study of the effect of compressive deformation on the random fabric, normal compressive tests were carried out with bulk specimens $20 \times 20 \times 70$ $\mathrm{mm}^{3}$. They were cut from Dye-3 ice core no. 120 (201 
$m$ depth) so that the long axis of the specimen was parallel to the core axis, and therefore, the specimen's compressive axis in the test coincided with that of the natural compressive stress in its original depth in the ice sheet. The c-axes, fabric of this core is almost random and its average grain size is approximately $2 \mathrm{~mm}$.

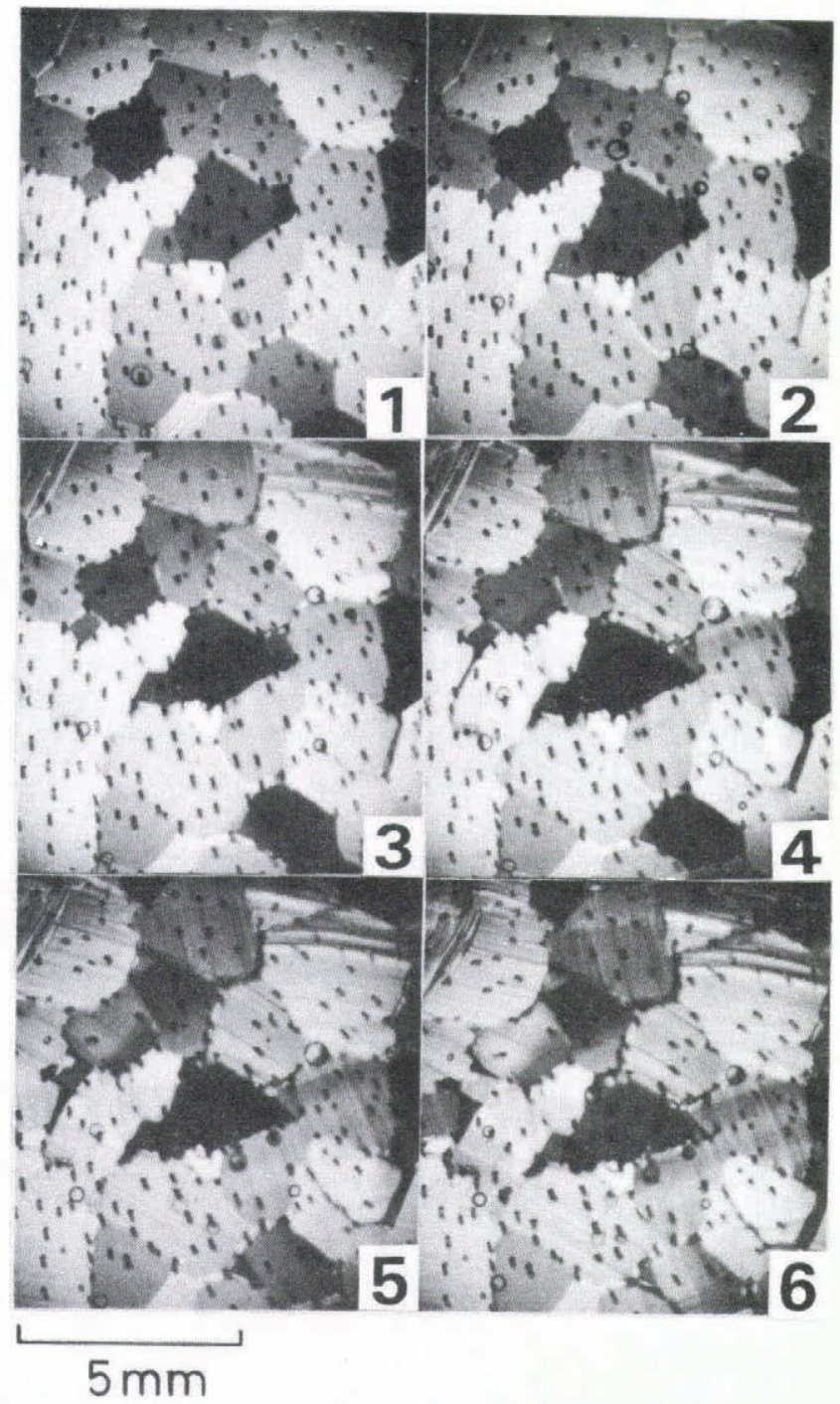

Fig.1. Photographs of a thin specimen through crossed polaroids during compressive deformation test no. 2 . Axial strain for each is: 1) $0 \%$, 2) $3.4 \%, 3) 6.5 \%, 4$ ) $10.0 \%, 5) 11.5 \%, 6) 12.4 \%$. Compression axis is in the top and bottom direction of the figure.

\section{Uniaxial compression tests of thin specimens}

Processes of the c-axis rotation were recorded on photographs of thin specimens intermittently taken on the process of uniaxial compression tests by transmitted light through the crossed polaroids which sandwiched the specimen. Thin sections of approximately $2 \mathrm{~mm}$ revealed clear images of individual grains and even of slip bands when they appeared by stress, as can be seen in Figure 1. Every compression test was carried out using a testing machine (for details of which see Higashi and Shoji 1979) under an atmospheric pressure or $20 \mathrm{MPa}$ hydrostatic pressure with a constant strain rate in the order of $10^{-7} \mathrm{~s}^{-1}$. Experimental conditions including temperatures and the characteristics of the used specimens are given in Table 1. The thin specimen was also sandwiched by transparent acryllic-resin boards to avoid the buckling which may take place when such a specimen is compressed perpendicular to the thin section. This arrangement gave plane strain conditions.

Since it is expected that the rotation of the c-axis in an individual grain is related to internal strain, the internal local uniaxial strain of each grain was determined by the relative movement of several air bubbles in it (black dots in Figure 1). The least-square method of evaluating the plane strain using several data is developed from the standard method (Nye 1957a).

\section{Uniaxial compression test of bulk specimens}

Uniaxial compression tests with bulk specimens for the study of fabric change were carried out with constant strain rate of $4.38 \times 10^{-7} \mathrm{~s}^{-1}$, under an atmospheric pressure. Experimental temperatures were $-13^{\circ} \mathrm{C}$ (test 5) and $-20^{\circ} \mathrm{C}$ (test 6 ). When the total strain reached $10 \%$, the test was terminated; the specimen was immediately removed from the testing machine and horizontal thin section specimens were prepared. Such procedures were carried out in a $-20^{\circ} \mathrm{C}$ cold room.

\section{EXPERIMENTAL RESULTS \\ Rotation of c-axes}

Figure 1 shows six successive photographs of a thin section specimen taken before the deformation and when the total strain of the specimen reached $3.4 \%$, $6.5 \%, 10.0 \%, 11.5 \%$ and $12.4 \%$ respectively in no. 2 test (Table 1). The slip bands appear in individual grain even when the total strain reached only $2 \%$ and they became clear as the strain increased. Since the c-axis must be perpendicular to the slip plane in each grain and it lay parallel to the plane of the wide area or to the plane of the figure, we can directly determine the c-axis of individual grains from these photographs. Angle $X$ between the specimen's compressive axis and the direction of the $c$-axis in each grain was measured using these determined $\mathrm{c}$-axis direction at various increasing value of strain. We will call $x$ the misorientation angle of a grain. Decreasing tendency of $x$ with increase of the strain can be clearly seen in Figure 2 in which

TABLE 1.

\begin{tabular}{|c|c|c|c|c|c|}
\hline $\begin{array}{l}\text { Test } \\
\text { no. }\end{array}$ & Specimen & Fabric & $\begin{array}{l}\text { Temp. } \\
0^{\circ} \mathrm{C}\end{array}$ & $\begin{array}{c}\text { Hydrostatic } \\
\text { Pressure } \\
\mathrm{MPa}\end{array}$ & $\begin{array}{c}\text { Strain Rate } \\
s^{-1}\end{array}$ \\
\hline 1 & $\begin{array}{l}\text { Artificial } \\
\text { Polycrystalline Ice }\end{array}$ & Random & -5 & 20 & $1.00 \times 10^{-7}$ \\
\hline 2 & $\begin{array}{l}\text { Artificial } \\
\text { Polycrystalline Ice }\end{array}$ & Random & -20 & 0.1 & $4.00 \times 10^{-7}$ \\
\hline 3 & Dye-3 Core, \#1851 & Single Maximum & -16 & 20 & $3.85 \times 10^{-7}$ \\
\hline 4 & Dye-3 Core, \#1950 & Single Maximum & -16 & 20 & $4.03 \times 10^{-7}$ \\
\hline 5 & Dye-3 Core, \#120 & Nearly Random & -13 & 0.1 & $4.38 \times 10^{-7}$ \\
\hline 6 & Dye-3 Core, \#120 & Nearly Random & -20 & 0.1 & $4.37 \times 10^{-7}$ \\
\hline
\end{tabular}




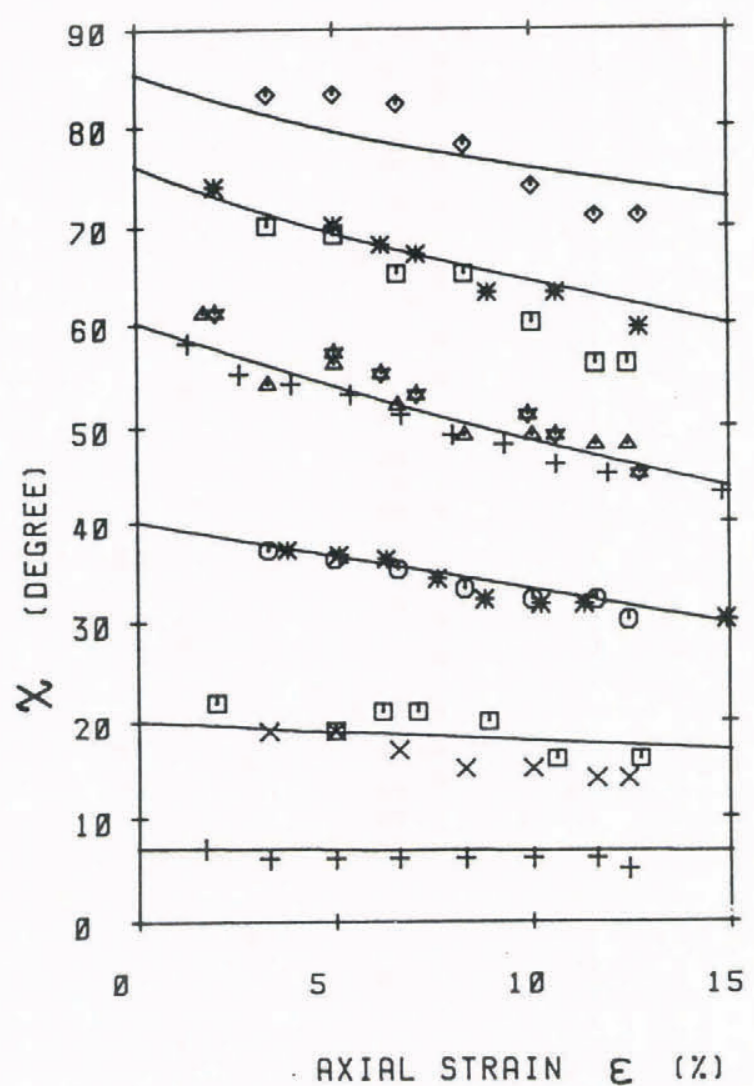

Fig.2. Changes of the misorientation angle $x$ with increasing strain $\epsilon$. Several grains of different initial angle $X_{0}$ are designated by different symbols. Solid lines show the relationship $X$ vs. $\epsilon$ by the equation 3 .

several examples of the change of $X$ from different values $x_{0}$ of various grains are plotted against the total strain $\epsilon$ of specimens. They indicate that the c-axis rotates in individual grains as the deformation proceeds and the larger the value $x_{0}$ the more rapid the rotation rate.

\section{Change of the random fabric}

Fabric diagrams for the originally undeformed, and deformed specimens in the tests at $-13{ }^{\circ} \mathrm{C}$ and $-20{ }^{\circ} \mathrm{C}$ are illustrated in circles of three diagrams of Figure 3 . This figure shows clearly that the c-axes become concentrated after the deformation, a tendency quantitatively expressed in the following way. Accumulated fraction curves as shown in Figure 4 are drawn by plotting the accumulated fraction $F(\theta)$ of number of $c$-axes within certain misorientation angle $\theta$ against the values of $\theta$ divided into $5^{\circ}$ intervals in this case. Three curves in Figure 4 exhibit $F(\theta)$ for three data sets corresponding to Figure $3(\mathrm{a})$, (b) and (c). The almost straight solid line for the initial random fabric change to those broken one for test no 5 and dotted one for test no 6 . They exhibit a steep slope below $40^{\circ}$ and gentle slope at larger angles than $60^{\circ}$, indicating the tendency that the fabric becomes concentrated toward $X$ approaches zero as the total strain increases. This process will be discussed and simulated in the next section with the aid of a formula obtained from the c-axes rotation process in the preceding subsection.

\section{DISCUSSION}

\section{Rotation of c-axes}

In the case of the compression test of a single crystal under restraint, it is well known that the norma to a slip plane rotates as it tends to become parallel to the compression axis (Schmid and Boas 1935). Since the basal plane is a dominant slip plane in ice crystal, the angle $X$ between the $c$-axis and the compression axis

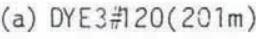

$130 C$

(b) TEST5

(c) TEST6

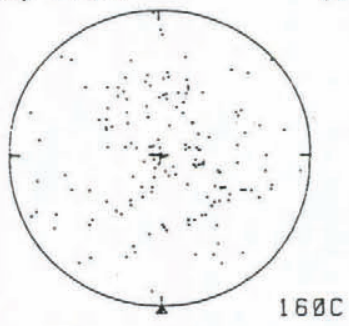

(d) SIMULATION

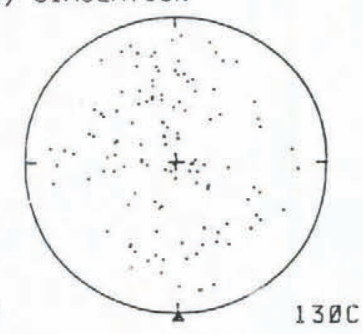

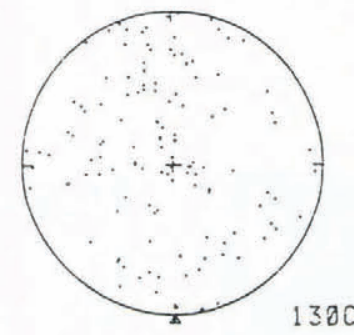

Fig.3. Change of the nearly random fabric of Dye-3 core no. 120 a) before the compression test, b) after test no. 5, c) after test no.6, and d) the simulated fabric diagram by equation 4 , starting from a) and strained $10 \%$. The center of each diagram coincides with the compression axis.

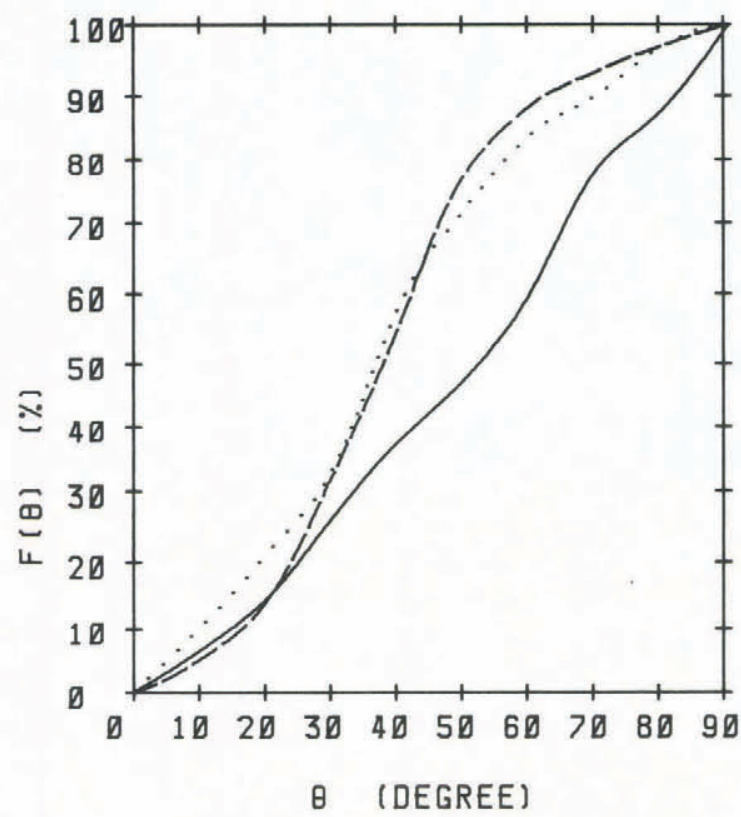

Fig.4. Cumulative fraction $F(\theta)$ curve for the fabrics of Dye-3 \#120 before the test ( - ), after test 5 (- - - ) and test $6(.$.$) .$

decreases from its initial value $X_{0}$ with increase of the compressive strain $\epsilon$ according to the following equation:

$$
\sin \mathrm{X}=\left(1-\epsilon_{\mathrm{S}}\right) \sin \mathrm{X}_{0}
$$

Individual grains in our thin specimens are considered to be restrained by their neighbours when they are deformed. Therefore, it is expected that the rotation of the c-axis of each grain could be correlated to the local compressive strain $\epsilon_{g}$ in the grain in such a way that $\epsilon_{\mathrm{g}}$ is inserted for $\epsilon_{\mathrm{S}}$ in eq. (1). $\epsilon_{\mathrm{g}}$ in individual grains may be proportional to the gross axial strain $\epsilon$ of the polycrystalline plane specimen with a proportional 


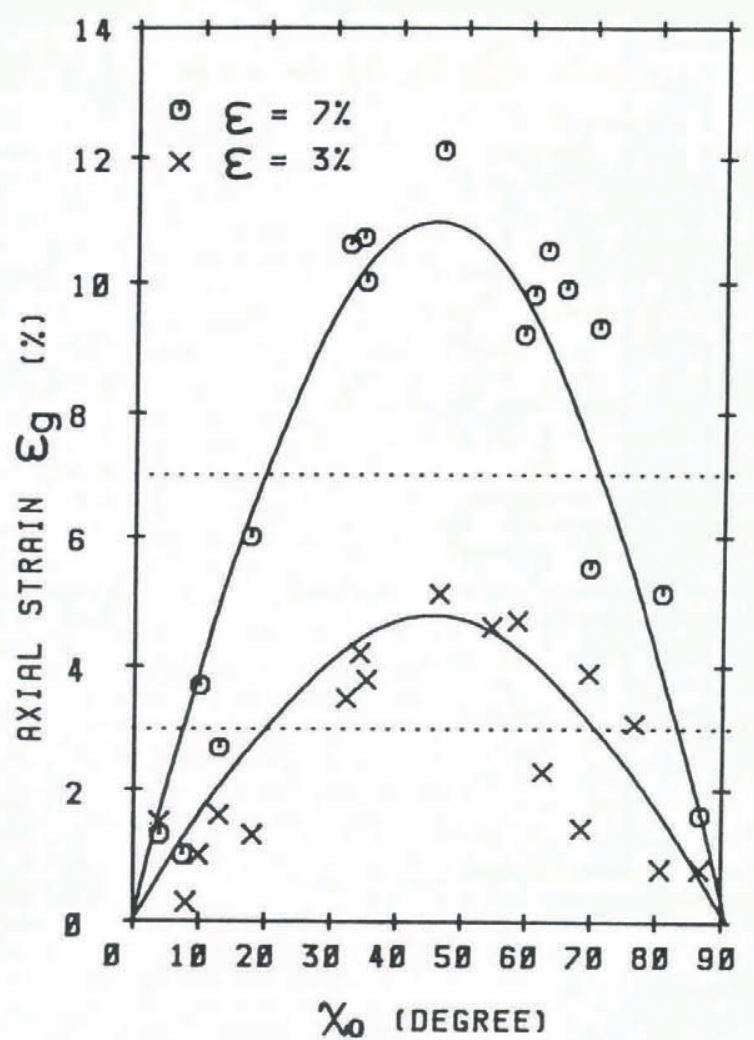

Fig.5. Relationship between the unixaial compressive strain $\epsilon_{\mathrm{g}}$ of individual grains which had initial misorientation angle $X_{0}$ after a certain total strain, $3 \%$ and $7 \%$. Solid lines show equation 2 .

constant as a function of $X_{0}$. Figure 5 shows relationships between the measured $\epsilon_{\mathrm{g}}$ of individual grains and their initial orientation angles $x_{0}$ at two stages when the total axial strain reached $3 \%$ and $7 \%$. Although data scatter considerably, they fit to the curve of an equation of the form:

$$
\epsilon_{\mathrm{g}}=\pi \epsilon \cos \mathrm{X}_{0} \cdot \sin \mathrm{x}_{0}
$$

This equation implies that the arithmetic mean of $\epsilon_{\mathrm{o}}$ over $X_{0}$ from $\mathrm{O}^{\circ}$ to $90^{\circ}$ is equal to the total axial strain $\epsilon$. Details of this implication together with its expansion to the three-dimensional case will be given elsewhere.

Inserting $\epsilon_{\mathrm{g}}$ of this equation for $\epsilon_{\mathrm{S}}$ in eq. (1), we obtain the changed orientation $X$ related to the total axial strain $\epsilon$ and the initial angle $X_{0}$ of the orientation in the following form:

$$
X=\sin ^{-1}\left[\left(1-\pi \in \cos X_{0} \sin X_{0}\right) \sin X_{0}\right]
$$

The solid lines in Figure 2 are the curves calculated by this equation (3) started from several certain initial $X_{0} s$. Good coincidence of the curves on the plotted empirical data of $X$ vs. strain suggests that the rotation mechanism of c-axes envisaged to obey equation (1) is valid.

\section{Formation of the broad single maximum fabric}

As was described in the preceding subsection, the nearly random fabric of ice at comparatively shallow core of Dye-3 tends to concentrate into the broad single maximum when its bulk specimen was uniaxially compressed. In view of the fact that the c-axes of individual grains rotate so that the misorientation angle tends to decrease to zero degree in a thin polycrystalline specimen during the compressive deformation as described above, it is inferable that the same mechanism takes place for the concentration process of the c-axes in the bulk polycrystalline ice. Therefore, it can be expected that the broad single maximum fabric will be produced in nature when polycrystalline ice body is subjected to the compressive deformation as the case in the upstream accumulation zone of an ice sheet.

For predicting the degree of c-axes concentration owing to the deformation, two computer simulations on the formation process of the broad single maximum fabric were carried out. The constitutive equation used for these simulations is as follows:

$$
\theta=\sin ^{-1}\left[\left(1-\mathrm{A} \Delta \epsilon \cos \theta_{0} \sin \theta_{0}\right) \sin \theta_{0}\right]
$$

This equation is of the same type as equation (3) because it should express the decreasing tendency of the misorientation angle $\theta$ with increasing strain. The angle $\theta$ is equivalent to $X$ in equation (3) but express the angle between the c-axis of individual grain and the compressive axis in a bulk polycrystalline specimen. Since the fabric pattern varies with increasing strain, the simulation should be performed stepwise with a certain strain interval $\Delta \epsilon$. The constant $\Pi$ in equation (3) is substituted by a parameter A which also varies with change of the fabric pattern.

The value of $A$ can be determined by the following equation which is derived from an empirical fact that the uniaxial strain of a bulk specimen $\epsilon$ is equal to the arithmetic mean of the uniaxial strain $\epsilon_{g}$ of whole individual grains:

$$
A=\frac{N}{\sum_{i=1}^{N} \cos \theta_{01} \sin \theta_{01}}
$$

where $\mathrm{N}$ is the total number of grains of which misorientation angle $\theta_{01}$ are measured. Angle $\theta_{\theta}$ in equation (4) is the initial value of $\theta$ at each step of the simulation: the real initial value for each grain at the start and the resultant of the preceding step for the next step. Different values of A near 3 according to equation (5) were used in successive steps. In practice for the present, $\Delta \epsilon$ was taken as $2 \%$.

The one simulation started from the fabric of Dye-3 no. 120 core which exhibited nearly random fabric as illustrated in Figure 3a. Fabric diagram shown in Figure $3 \mathrm{~d}$ is the resultant fabric when reached $10 \%$. It is comparable to those obtained by compression tests as illustrated in Figures $3 \mathrm{~b}$ and $3 \mathrm{c}$. Another simulation was carried out starting from an artificially-made random fabric as shown in Figure $6 \mathrm{a}$ in which 200 orientation of $\mathrm{c}$-axes were selected by the use of random number generated in the computer. Results of
(a)RANDOM

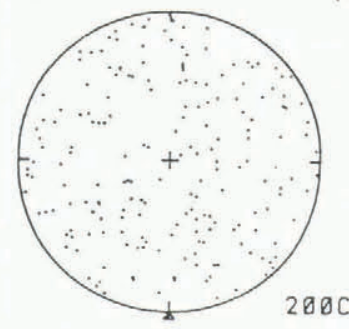

(c) STRAIN $30 \%$

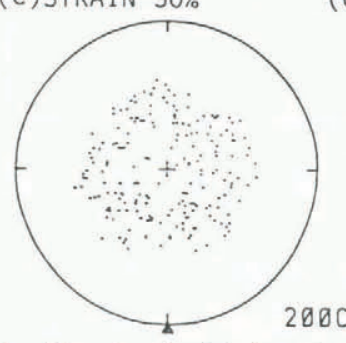

(b)STRAIN $10 \%$

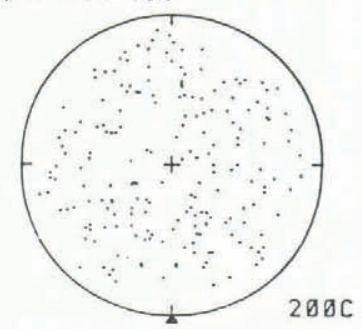

$2 ø \varnothing c$
(d)STRAIN $50 \%$

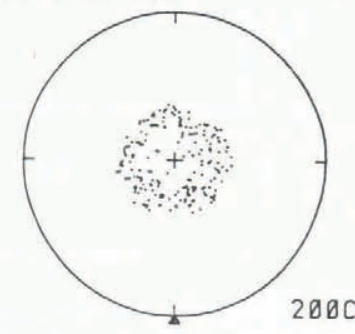

Fig.6. Simulated fabric diagrams started from artificially made random fabric with various degrees of uniaxial compressive strain. The compressive axis is in the center of each diagram. 


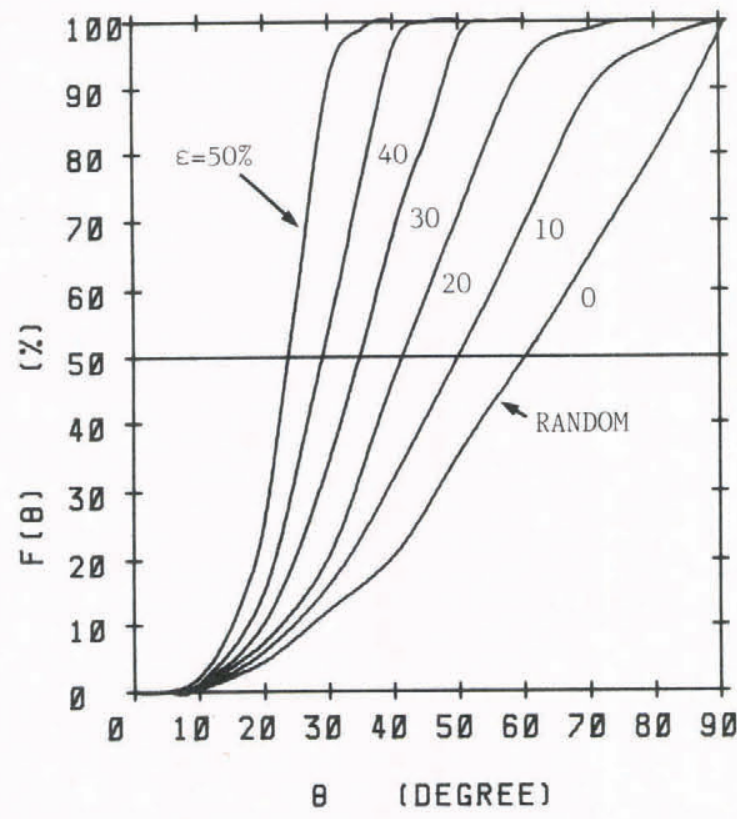

Fig.7. $F(\theta)$ - $\theta$ curve for the simulated fabrics shown in Fig. 6.

the simulation at $10 \%, 30 \%$ and $50 \%$ of the total compressive strain are given in Figures $6 \mathrm{~b}, 6 \mathrm{c}$ and $6 \mathrm{~d}$.

$F(\theta)$ curves, the accumulated fractions of the c-axes within $\theta$ are drawn in Figure 7 from such calculations as performed for the above simulation. The figure clearly shows that the broadness of the c-axes concentration decreases as the total strain increases. If we draw a horizontal line at a level of $50 \%$ of $F(\theta)$ in Figure 7 , its intersections with the predicted curve of $F(\theta)$ at various total strain $\epsilon$ give us the angle $\theta$ or the inclination from the compression axis at which the number of grains are halved in the fabric diagram. This is called the median inclination $\boldsymbol{\theta}_{\mathrm{m}}$ and a good indicator of the degree of concentration of the c-axes in the fabric. The strain dependence of $\theta_{m}$ obtained from

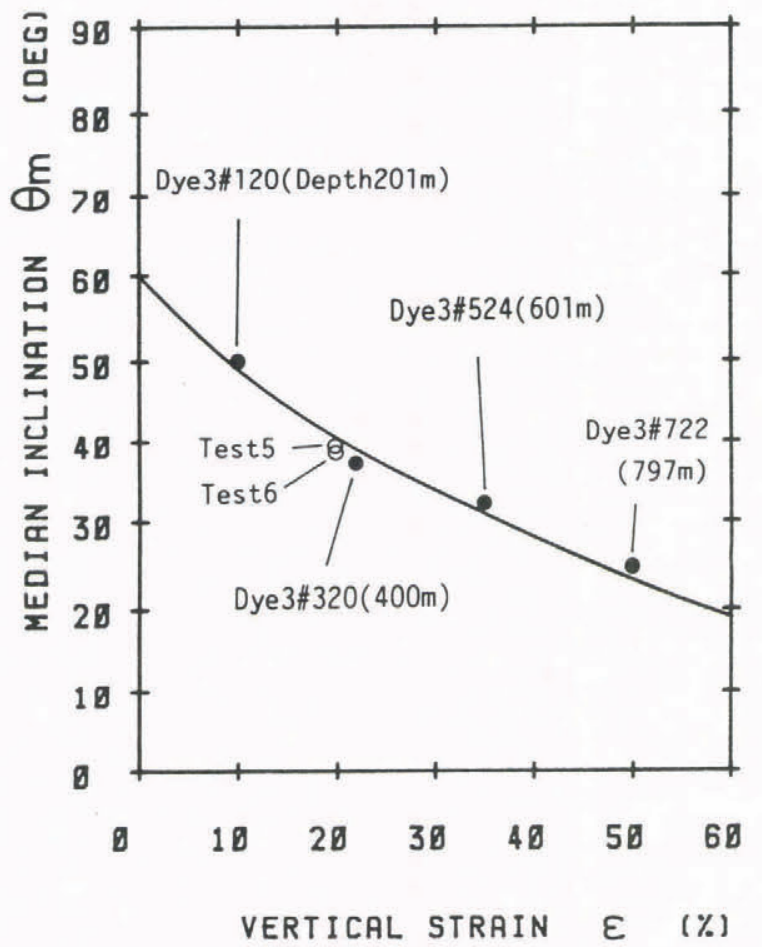

Fig.8. Relationship between the median inclination $\theta_{m}$ and the vertical strain for the Dye-3 core ice and specimens of compression tests. The solid line shows the strain dependence of $\theta_{\mathrm{m}}$ obtained from results of simulated fabrics. results of the above simulation is given as a solid line in Figure 8.

Individual relationships between the median inclination $\theta_{m}$ for the observed fabrics of specimens of ice core from various depths at Dye 3, Greenland and their given vertical strain $\epsilon$ are plotted on this figure (closed circles). The data for specimens of compression test no 5 and no 6 are also plotted (open circles). The vertical strain given to the ice at a certain depth was estimated by a simple calculation based on Nye's flow model (Nye 1957b), assuming that the ice thickness and the accumulation rate has not changed during the past few thousand years. The accumulation rate used for the calculation is the measured value of $0.54 \mathrm{ma}^{-1}$ at Dye 3 (Reeh and others 1978). For specimens of the uniaxial compression tests, the vertical strain was given by adding the compressive strain of $10 \%$ to the calculated vertical strain of $10 \%$ corresponding to the depth $201 \mathrm{~m}$ of specimen no. 120.

Field data and empirical results plotted on the figure fit fairly well with the solid line. This proves that the formation mechanism of the broad single maximum of the fabrics of ice cores from the depth of plateau area of Greenland ice sheet is principally the rotation of c-axes in individual grains composing the ice in it. This is believed to be generally true in polar ice sheets in which recrystallization does not occur intensively because of low temperatures.

\section{ACKNOWLEDGEMENTS}

We thank Professor C C Langway, Jr for providing ice core samples of Dye-3, and $\mathrm{Dr} \mathrm{T}$ Hondoh and $\mathrm{Dr} \mathrm{M}$ Nakawo for useful discussion while preparing this paper.

\section{REFERENCES}

Duval P 1981 Creep and fabrics of polycrystalline ice under shear and compression. Journal of Glaciology 27(95): $129-140$

Higashi A, Shoji H 1979 [Mechanical tests of Antarctic deep core ice under hydrostatic pressure; instrumentation and preliminary results]. Oyo-butsuri 48(1): $41-47$

Huang M, Ohtomo M, Wakahama G 1982 [Repeated recrystallization of polycrystalline ice]. Low Temperature Science A41: 13-23

Jones S J, Brunet J G 1978 Deformation of ice single crystals close to the melting point. Journal of Glaciology 21(85): 445-455

Kamb B 1972 Experimental recrystallization of ice under stress. Geophysical Monograph 16: 211-352

Nye J F 1957a Physical properties of crystals. Oxford, Oxford University Press

Nye J F 1957b The distribution of stress and velocity in glaciers and ice sheets. Proceedings of the Royal Society of London A, 239(1216): 113-133

Reeh N, Clausen H B, Dasgaard W, Gundestrup N, Hammer C U, Johnsen S J 1978 Secular trends of accumulation rates at three Greenland stations. Journal of Glaciology 20(82): 27-30

Rigsby G P 1960 Crystal orientation in glacier and experimentally deformed ice. Journal of Glaciology 3(27): $589-606$

Schmid E, Boas W 1935 Kristallplastizitat. Berlin, Springer-Verlag

Shumskii P A 1958 The mechanism of ice straining and its recrystallization. Symposium of Chamonix, IASH Publ 47: 244-248

Steinemann S 1958 Experimentalle Untersuchungen zur Plastizitat von Eis. Beitrage zur Geologie der Schweiz. Geotechnische Serie. Hydrologie, 10

Tanaka H 1972 On preferred orientation of glacier and experimentally deformed ice. Journal of Geological Society of Japan 78(12): 659-675

Wakahama G 1964 [On the plastic deformation of ice. V. Plastic deformation of polycrystalline ice]. Low Temperature Science, A22: 1-24

Watanabe O, Oura H 1968 [Experimental studies on orientation of polycrystalline ice by unconfined compression 1]. Low Temperature Science, A26: 1-28 